\title{
Convencionalização e apropriação na agricultura orgânica: análise entre agricultores da região meridional brasileira
}

\author{
Lillian Bastian ${ }^{1}$ \\ Nadir Paula da Rosa ${ }^{2}$
}

\begin{abstract}
RESUMO
A apropriação da produção dos insumos e da fabricação das ferramentas agrícolas por atores não agricultores foi um processo propagado pela Revolução Verde. Atualmente, essa apropriação vem sendo identificada entre as agriculturas de base ecológica concatenando-se ao processo de convencionalização dos orgânicos. Neste sentido, este artigo tem como objetivo averiguar se o processo de apropriacionismo é visualizado entre agricultores orgânicos certificados. Para essa averiguação, coletaram-se dados com agricultores e técnicos. E a apropriação foi verificada para os seguintes insumos: adubos, compostos, biofertilizantes, defensivos naturais e sementes. Os resultados encontrados denotam uma apropriação, principalmente, ao nível dos adubos e compostos. Ademais, há um incipiente processo de integração entre agroindústria e agricultores orgânicos. Entretanto, ressalta-se que a agricultura orgânica apresenta uma característica que facilita a independência de insumos externos: a autossuficiência em termos de renovação da fertilidade do solo nos agroecossistemas que se encontram em estado equilibrado e são diversificados.
\end{abstract}

Palavras-Chaves: agricultura orgânica; insumos; apropriação dos processos produtivos; convencionalização dos mercados de orgânicos.

\section{Conventionalization and appropriation in organic agriculture: analysis between farmers in the brazilian southern region}

\begin{abstract}
The appropriation of the production of inputs and the shape of agricultural tools by non-agricultural actors was a process propagated by the Green Revolution. Currently, this appropriation has been identified among ecologically based agriculture, connected to the process of conventionalization of organic. In this sense, the aim of this article is to investigate whether the process of appropriation is viewed among certified organic farmers. For this investigation, data were collected from farmers, technicians and a researcher. From the totality of products and processes that may be appropriated by the agroindustrial capital were selected inputs: fertilizers, compounds, biofertilizers, natural defenses and seeds. The results show a appropriation, mainly, of fertilizers and compounds. In addition, there is an incipient process of integration between industry and organic. However, it should be pointed out that organic agriculture has a characteristic that facilitates the independence of external inputs, which is self-sufficiency in terms of renewal of soil fertility in agroecosystems that are in a balanced state and are diversified.
\end{abstract}

Key-Words: organic farming; inputs; appropriation of the productive processes; conventionalization of organic markets.

\section{INTRODUÇÃO}

Pesquisas de mercado demonstram que o setor de orgânicos do Brasil tem aumentado em média 20\% ao ano desde os anos 2000 (SEBRAE, 2015, IDEC, 2010). Dados do Ministério da Agricultura, Pecuária e Abastecimento (MAPA) dão a estimativa dessa expansão. No cadastro de 2014, havia 6.719 unidades produtivas certificadas (BRASIL,

\footnotetext{
1 Pesquisadora do Instituto de Pesquisa Econômica Aplicada (Ipea), Doutora em Desenvolvimento Rural, Programa de Pós-Graduação em Desenvolvimento Rural da Universidade Federal do Rio Grande do Sul. Email: lillianbastian12@gmail.com

2 Docente do Instituto Federal Catarinense /IFC -Campus Videira. Doutora em Desenvolvimento Rural, Programa de Pós-Graduação em Desenvolvimento Rural da Universidade Federal do Rio Grande do Sul.
} 
2015). Por sua vez, a última planilha de $1^{\circ}$ de Julho de 2021 do cadastro demonstra que atualmente são aproximadamente 24.684 destas unidades certificadas no Brasil (BRASIL, 2021).

Além do aumento de unidades produtivas certificadas orgânicas, outros atores do mercado de alimentos têm adentrado no ramo dos orgânicos, como grandes redes varejistas e empresas privadas. Acompanhando este processo, proliferaram-se organismos de certificação e se reposicionaram mediadores políticos (NIEDERLE; ALMEIDA, 2013). Destaca-se que essas transformações relacionam-se com a conscientização de distintos segmentos da sociedade sobre a qualidade dos alimentos.

Esse alargamento do mercado de orgânicos, entrada de novos atores de perfis variados, bem como a conscientização das pessoas sobre as características, condições e qualidades dos alimentos, conduz a alterações que diversificam as expressões dos mercados de orgânicos (SAUTEREAU; BELLON, 2012). Para compreender melhor estas transformações, já foram produzidas algumas investigações. Destacam-se aqui as de Buck, Getz e Guthman (1997), Oelofse et al. (2011), Almeida e Abreu (2009), e Rover e Lampa (2013). Nestas investigações demonstrou-se que, dentre as novas configurações dos mercados de orgânicos, surgiram algumas características de operação e organização similares as existentes na cadeia produtiva da agricultura agroquímica convencional. Estas características foram denominadas de convencionalização.

A apropriação é uma das alterações recentes dos mercados de orgânicos que está vinculada a convencionalização dos orgânicos. Conforme Goodman, Sorj e Wilkinson (2008), apropriacionismo revela-se pelo desaparecimento ou redução significativa de processos antes inerentes as unidades produtivas. Dentre estes processos estão a produção de adubos e a reprodução de sementes, por exemplo. Que com o apropriacionismo são produzidos nos limites externos das propriedades reconfigurados na forma de insumos.

Este artigo relaciona-se com esse debate da convencionalização e foca-se especificamente na apropriação da fabricação dos insumos orgânicos por agentes não agricultores. Objetiva averiguar se o processo de apropriacionismo é visualizado entre agricultores orgânicos certificados residentes em regiões dos estados de Santa Catarina e Rio Grande do Sul. Para isso, foram selecionados agricultores orgânicos certificados e técnicos. A metodologia usada foi estudos de caso, conversas informais além de acesso a dados secundários.

Essa investigação apresenta relevância ao expor transformações que se encontram em curso nos mercados de orgânicos. Estruturalmente, o artigo está dividido em sete seções. A primeira parte é esta introdução. Na sequência apresenta-se a revisão da literatura sobre convencionalização dos orgânicos e sobre o apropriacionismo. Essa parte é seguida pela seção da metodologia. A quinta seção é a dos resultados. Uma sexta seção é a discussão dos resultados a partir da literatura e, por último, são apresentadas algumas considerações finais.

\section{O PROCESSO DE CONVENCIONALIZAÇÃO DE ORGÂNICOS}

O debate acerca da convencionalização dos orgânicos teve início com a publicação de Buck, Getz e Guthman (1997). Além de similaridades operacionais e organizacionais com a agricultura agroquímica convencional, os autores identificaram simplificação dos princípios da agricultura orgânica (IFOAM, 2005). A partir dessa primeira pesquisa, outras averiguações foram conduzidas em distintos contextos nos países da Nova Zelândia, Canadá, Holanda, Brasil, dentre outros. Nessas investigações, relatou-se a aparição de diferentes nuances da convencionalização. Ou seja, os sinais de convencionalização são particulares de acordo com as especificidades locais. 
Dentre esses sinais destacam-se: a dependência de insumos externos à propriedade, a especialização da produção, o excesso de nitrato no solo, a ausência de preocupação quanto à origem (agroquímica ou orgânica) dos insumos, a intensificação de capital, a substituição de trabalho manual pelo mecanizado e o interesse estritamente econômico na atividade da agricultura orgânica (HALL, MOGYORODY, 2001, GUTHMAN, 2004, LAMINE; BELLON, 2009, OELOFSE et al. 2011, ABREU et al. 2012).

As normas de certificação que atestam a conformidade orgânica desempenham um papel que, impremeditadamente, favorecem a convencionalização. A grande maioria das agências de certificação são incapazes de incluírem todos os aspectos inerentes à agricultura orgânica expressos nos seus princípios (IFOAM, 2005). Há carência dos princípios relacionados com biodiversidade, reciclagem de nutrientes e considerações sociais, por exemplo. As normas são exitosas em incluir produtos e técnicas aceitáveis e permitidos certificando parcialmente os alimentos orgânicos.

No Brasil, dentre os sinais da convencionalização tem-se a mecanização no controle de ervas adventícias, (Oelofse et al.; 2011); a compra de agroindústrias orgânicas por corporações do ramo dos alimentos $(\mathrm{G1}, 2017)$; a pouca oferta de sementes orgânicas (PARRA FILHO et al., 2018), ou a demora para os mercados de orgânicos se organizarem - o que não necessariamente é um sinal de convencionalização. Também se tem a agricultura orgânica baseada em mera substituição dos insumos de origem agroquímica pelos orgânicos e a especialização produtiva (CANDIOTTO; MEIRA, 2014; ALMEIDA; ABREU, 2009) acompanhada da dependência de insumos externos (OELOFSE et al. 2011).

Conforme as últimas pesquisas empíricas apontadas acima, é possível conhecer algumas das heterogêneas alterações que vêm ocorrendo no setor de orgânicos e que se relacionam com o processo de convencionalização dos orgânicos. Segue-se nesse momento para a subseção acerca da noção de apropriacionismo.

\section{APROPRIACIONISMO NO CONTEXTO DA AGRICULTURA ORGÂNICA}

As transformações inerentes ao processo de convencionalização de orgânicos apresentam alguns elementos do que foi definido como apropriacionismo por Goodman, Sorj e Wilkinson (2008). Por apropriacionismo compreende-se a diminuição do papel da natureza na produção agrícola por meio da reestruturação constante do processo de produção rural na medida em que os capitais agroindustriais exploram novas oportunidades de acumulação. $\mathrm{O}$ processo que culminou na atual apropriação de insumos necessários à produção agrícola durou aproximadamente uma centena de anos. E foi marcado por distintas incorporações industriais dos processos até então inerentes ao rural (GOODMAN, SORJ, WILKINSON, 2008, p. 3).

A apropriação à qual esse artigo se refere nada mais é do que o entendimento que, em período anterior da história, os agricultores tinham suas maneiras e materiais para renovar a fertilidade do solo, reproduzir as sementes e produzir equipamentos para seus cultivos. Ao decorrer de um período longo, o capital agroindustrial passou a produzir esses materiais e equipamentos necessários à produção agrícola e oferece-los aos agricultores na forma de insumos. A partir do momento que alguns dos processos agrícolas são reproduzidos industrialmente, ocorre a sua apropriação pelo capital industrial. Esse processo de apropriação pode conduzir (e conduziu uma proporção significativa das unidades produtivas rurais) à dependência de mercados.

A adoção da interpretação da mudança da base técnica na agricultura a partir do apropriacionismo remete a um rol variado de inovações que ocorreram no âmbito da cadeia alimentar quando a agricultura era parcialmente mercantilizada. Com essa compreensão, 
atribui-se destaque à forma como os recursos produtivos tiveram as dinâmicas de produção e reprodução alteradas. A compreensão da apropriação como um rearranjo de produtos, serviços e atores da cadeia produtiva da agricultura agroquímica pode ser trazida para auxiliar, metodologicamente e teoricamente, na compreensão das atuais transformações dos mercados de orgânicos que são denominadas de convencionalização.

\section{METODOLOGIA}

De modo inicial, esclarece-se que, nesse artigo, a conceituação de agricultura orgânica adotada é a definida pela Federação Internacional dos Movimentos da Agricultura Orgânica (IFOAM, 2005), que caracteriza agricultura orgânica conforme os princípios de saúde, ecologia, justiça e precaução. Desse modo, a compreensão desse modo de fazer agricultura é mais ampla do que a concepção de substituição de insumos, aproximando-se do entendimento de agricultura ecológica como aquela em que se adotam medidas de redesenho de agroecossistemas (ALTIERI, NICHOLLS, 2003).

Optou-se pela investigação da apropriação pelo capital agroindustrial dos compostos, sementes, biofertilizantes, caldas, adubos orgânicos e defensivos naturais comumente usados na produção agrícola vegetal orgânica. Trata-se de uma pesquisa qualitativa (GODOY, 1995), com uso de técnicas de entrevistas semiestruturadas, observação participante e diários de campo.

Os dados da pesquisa são secundários e primários. Os primeiros foram obtidos em sites eletrônicos das empresas produtoras de insumos orgânicos mencionadas nas entrevistas com os agricultores. E os primários são decorrentes de casos específicos em três regiões dos estados de Santa Catarina e Rio Grande do Sul: Meio Oeste Catarinense e Sul Catarinense e Centro Sul no Rio Grande do Sul. Segundo Stake (2000), os casos específicos caracterizam-se pela singularidade de que as informações que são coletadas sobre o fenômeno investigado são averiguadas de modo profundo a fim de possibilitar a ampliação dos conhecimentos sobre o problema em estudo (MATTAR, 2001).

Os dados primários também foram obtidos por meio de pesquisa paralela. Nesta pesquisa, serviu-se de técnicas como conversas informais realizadas a partir de questões chave e anotações em diários de campo. Essa pesquisa ocorreu nos dois estados acima mencionados mais São Paulo e Paraná. Na tabela 1 constam o número de atores consultados na pesquisa paralela e a sua localização.

Optou-se por casos de agricultores especializados na produção de poucas culturas por apresentarem tendência à dependência externa de insumo. No entanto, além dos agricultores especializados, um agricultor com produção diversificada foi incluído na investigação. Este agricultor diversificado auxiliará a corroborar (ou não) com a hipótese de que agricultores especializados são mais dependentes de insumos externos.

Tabela 1: Tipologia, localização e forma de acesso aos dados

\begin{tabular}{l|l|l|l|l}
\hline Atores & Número & Localização & $\begin{array}{l}\text { Dados } \\
\text { secundários }\end{array}$ & $\begin{array}{l}\text { Dados } \\
\text { primários }\end{array}$ \\
\hline Agricultores & 4 & $\begin{array}{l}\text { Tapes, Harmonia, RS } \\
\text { Santa Rosa de Lima, SC } \\
\text { Colombo, PR }\end{array}$ & 4 \\
\hline $\begin{array}{l}\text { Produtores de } \\
\text { insumos }\end{array}$ & 3 & $\begin{array}{l}\text { Harmonia, Montenegro, RS } \\
\text { Mogi Mirim, SP }\end{array}$ & 2 & 1 \\
\hline Técnicos & 2 & $\begin{array}{l}\text { Sertãozinho, SP } \\
\text { Curitiba, PR }\end{array}$ & & 2 \\
\hline
\end{tabular}

Fonte: pesquisa de campo (2019). 


\section{OS DADOS GERADOS A CAMPO}

Nesta seção serão apresentados os dados coletados. Inicia-se pelo agricultor especializado na produção de soja, em rotação com milho. Na sequência vem o agricultor produtor de shiitake. O último dos casos, é do agricultor diversificado que é certificado de forma participativa. Ao final desta seção, são trazidos os dados gerados com base em conversas informais com outros agricultores, mas também com técnicos.

\subsection{Produtor de milho e soja da região Meio Oeste Catarinense, Santa Catarina}

A área em que há produção orgânica localiza-se na região Meio Oeste Catarinense. A área total cultivada pelo agricultor é de 155 hectares. Destes, 57 hectares são ocupados com agricultura orgânica e certificada. Não houve conversão integral da área devido aos maiores cuidados necessários no cultivo orgânico. Esse produtor começou com dois hectares de arroz orgânico. Em 1996, passou para a produção de soja e milho orgânicos. Essa mudança ocorreu porque o arroz não se mostrou a melhor cultura dadas as características edafoclimáticas. A cultura da soja iniciou em campo nativo, por isso não houve período de transição. Já iniciou produzindo com o selo orgânico. O cultivo em solo que estava em pousio favoreceu para uma baixa incidência de ervas adventícias. Esse problema não existia no começo. $\mathrm{O}$ agricultor faz plantio direto há 26 anos. Atualmente, o produtor costuma fazer rotação de culturas entre soja e milho ou outras gramíneas. Ele destaca que o milho é a planta de maior retorno de matéria orgânica para o solo. Esse milho também é orgânico e comercializado com a mesma empresa para a qual a soja é vendida.

Quanto aos insumos utilizados na propriedade, ele os adquire em vários estabelecimentos. A semente e alguns insumos, por exemplo, compra da empresa com a qual comercializa a produção. Quanto às caldas e compostos, são produzidos dentro da propriedade pelo produtor, obedecendo às orientações da certificadora ECOCERT. Em relação ao fosfato natural, potássio, enxofre, sulfato de cobre, calcário, silicato de sódio e cal hidratada são adquiridos em cooperativas ou revendas de produtos agrícolas da região as quais comercializam os insumos para a agricultura agroquímica. Observa-se que as empresas produtoras desses insumos são as mesmas fabricantes dos insumos para a agricultura agroquímica.

O agricultor possui aviários em sua propriedade e, por meio de um processo também orientado pela certificadora, transforma as camas de aviários em compostos. Enfatiza que a maior parte da adubação de sua lavoura vem da matéria orgânica oriunda de forrageiras utilizadas como cobertura de solo. Por exemplo, o nabo e as aveias. A aveia preta apresenta bom retorno de massa seca e inibe a incidência de plantas invasoras. As diferentes coberturas verdes (aveia preta, aveia branca, nabo, centeio e trigo), manejadas de maneira correta, favorecem consideravelmente a dizimação de gramíneas. E, em últimos casos, nas beiradas das lavouras se utiliza a enxada para retirar a buva, uma invasora que se propaga pelo vento. São obrigatórias as barreiras naturais nas bordas da lavoura orgânica. Elas são feitas com dois tipos de capim elefante. Quando da divisa de estradas, também se preserva a vegetação natural.

Destaca que no cultivo orgânico o cuidado deve ser diário. Detectada alguma anormalidade, rapidamente se atua com algum produto para fazer a prevenção ou o controle. Essa particularidade do cultivo orgânico é o que impede a integral conversão orgânica das áreas cultivadas pelo agricultor. Para controlar as possíveis anormalidades que podem surgir, faz-se uso de diferentes produtos permitidos, certificados orgânicos, aplicados em quantidades 
e períodos do dia determinados. O silicato de sódio e o enxofre funcionam como fungicida. Para o controle da aveia involuntária, usa-se especificamente o sulfato de cobre, também utilizado para controlar as lesmas e caramujos. Já o oxicloreto de cobre, calda sulfocálcica e calda bordalesa como fungicidas, para controlar a ferrugem e o oídio. O oxicloreto de cobre é o principal fungicida para ferrugem asiática.

Além desses produtos e manejo, usa-se o inoculante tanto na cultura da soja como na do milho. Isso permite alta concentração de nitrogênio no solo. Parte desse nitrogênio é retida na palha das culturas e coberturas. A inoculação influencia no ciclo do nabo impedindo que as sementes fiquem viáveis para germinar. Outras fontes de nitrogênio são tortas de mamona e salitre do Chile.

\subsection{Produtor de Cogumelo Shiitake da Região Centro Sul, Rio Grande do Sul}

O segundo caso investigado localiza-se no estado do Rio Grande do Sul, na região Centro Sul. A área total da propriedade estudada é de 5,5 hectares onde há produção comercial de cogumelos shiitake (Lentinula edodes) em 0,5 hectares. A certificação é pela ECOCERT. Não foi necessário um período de transição, pois no local onde atualmente há a produção de cogumelos, não havia uso de agrotóxicos e demais insumos químicos. $\mathrm{O}$ agricultor produz shiitake há quatro anos. O seu cultivo do cogumelo shiitake ocorre em ambiente tecnificado, com estruturas físicas de filtros e controles as quais evitam a utilização de agrotóxicos durante o processo de produção. Essas estruturas físicas possibilitam que o ambiente onde ocorre a produção de shiitakes seja o mais estéril possível. Segundo o agricultor, há necessidade de um ambiente esterilizado e limpo na produção orgânica de shiitakes, porque o alimento dos cogumelos é o mesmo alimento consumido por bactérias e outros fungos.

Nesse ambiente limpo e artificialmente climatizado, os insumos necessários para a produção são serragem, farelos (de trigo e/ou arroz), água e calcário. Esses insumos não possuem certificação orgânica. A serragem possui certificação de madeira não tratada. Os farelos são rejeitos de uma indústria de farinha e massas localizada na região Centro Sul. A serragem é proveniente de uma serraria localizada no mesmo município do agricultor. A partir desses insumos, o agricultor produz um composto que passa por processos de autoclavagem. Após essa esterilização, o composto recebe o micélio do shiitake, um pedaço do tecido do fungo. Então é ensacado. Esse saco em que está o composto com o micélio inoculado contém apenas uma abertura, um filtro para "respiração". Esses sacos são armazenados e manejados em câmaras climatizadas durante 60 dias. Após esse período, quando o fungo vai crescer, o bloco do composto é desensacado e colocado em prateleiras de outras câmaras climatizadas. A sacaria utilizada na produção dos cogumelos é específica para a produção do shiitake em bloco.

Outro aspecto mencionado pelo agricultor é a existência de empresas e produtores de shiitake fabricantes do micélio inoculado que, posteriormente, vendem esses micélios para outros produtores que não possuem a parte de laboratório para a produção de micélio em suas propriedades.

\subsection{Produtor Diversificado na Região Sul de Santa Catarina}

O terceiro agricultor consultado, localiza-se no estado de Santa Catarina, na região Sul Catarinense. Trata-se de uma propriedade diversificada, trabalhando exclusivamente com produtos orgânicos. A área total da unidade produtiva é de 19 hectares sendo toda certificada de forma participativa pela Rede Ecovida de Agroecologia. Desses 19 hectares, quatro 
hectares são utilizados com ocupação agrícola. No entanto, a unidade como um todo não recebe nenhum insumo de origem química. Atualmente, a área de quatro hectares é ocupada com abacaxi ( 0,3 ha), morango ( 0,1 ha), milho e feijão ( 0,3 ha), alho e cebola $(0,1$ ha), café ( $0,2 \mathrm{ha})$, cana de açúcar $(0,2 \mathrm{ha})$ e o restante da área não utilizada fica em pousio ou com adubação verde.

O processo de transição durou de 1996 a 2000, ano da finalização da utilização de agrotóxicos. Outra mudança ocorrida na propriedade foi que, com o avanço dos processos de ciclagem de nutriente, de 2000 a 2004, suspendeu-se o uso de adubos sintéticos. Com essa evolução, entre os anos de 2003 e 2004, buscou-se a primeira certificação.

O agricultor relatou que os insumos utilizados para a produção orgânica são obtidos de diversas formas. As sementes de feijão, milho, mucuna, feijão de porco, arroz de sequeiro, abóbora, moranga, bem como mudas de bananeira, abacaxi, morango, alho, café, são obtidos por meio de materiais genéticos oriundos da própria unidade de produção. Outrossim, essas variedades locais são adaptadas ao clima e solo da unidade produtiva. Para a semeadura de verduras utilizam-se sementes convencionais, pois não há disponibilidade destas sementes orgânicas na região. Porém produzem-se as mudas em bandejas. A produção das mudas é conduzida de forma orgânica, não usando adubos sintéticos e nem pesticidas químicos.

$\mathrm{Na}$ adubação, utiliza-se esterco de gado e galinha, animais da própria unidade produtiva. $\mathrm{O}$ esterco de aves não é suficiente, então o complemento é feito com a aquisição de cama de aviário de produção de frangos convencional, adquirida de aviários próximos à unidade produtiva. Esses estercos são deixados para estabilizar por 6 meses antes da utilização. Também se utiliza na propriedade adubação verde com mucuna, feijão de porco para evitar o uso de estercos. Outra técnica é o uso de pousio.

$\mathrm{O}$ tratamento para frear o avanço de eventuais doenças fúngicas e algumas bacterioses é feito com calda bordalesa sulfato de cobre adicionado de cal virgem e água. A urina de vaca em lactação, das vacas da propriedade é usada como biofertilizante. Também são feitas na propriedade as caldas de urtiga, pimenta e samambaia. Outra estratégia para amenizar a incidência de doenças é a rotatividade entre os cultivos, principalmente entre as culturas de abacaxi e morango. De fora da propriedade são adquiridos apenas a calda bordalesa e o esterco da cama de aviário.

A produção do abacaxi inicia com uma roçada mecanizada da cobertura vegetal, posteriormente uma aração e seleção das mudas sadias. Procede-se ao plantio e aos seis meses deste, aduba-se com cama de aviário no interior da fileira dupla, aproximadamente 5.000 $\mathrm{kg} / \mathrm{ha}$. Repete-se o procedimento aos 14 meses após o plantio. No intervalo entre o plantio e os 14 meses são realizadas três aplicações de urina de vaca na concentração de 400 $\mathrm{ml} / 10$ litros de água. Aos vinte meses, procede-se à tapação manual dos frutos com folha de jornal, para evitar radiação solar direta. Já aos vinte e dois meses após o plantio é realizada a colheita.

\subsection{Dados Coletados em Conversas Informais com Agricultores e Técnicos}

Em pesquisa realizada com agricultores orgânicos dos estados do Rio Grande do Sul, Santa Catariana e São Paulo, observou-se que na agricultura orgânica certificada são usados insumos não necessariamente certificados. Os agricultores são orientados pelas certificadoras, participativa e de terceira parte, a usar insumos com a qualidade orgânica caso estejam disponíveis no mercado. Caso não encontrem os insumos com essa qualidade, são autorizados a usar insumos não certificados ou provenientes da agricultura convencional.

Essa é uma prática que vem sendo aceita pelas certificadoras até os mercados de orgânicos se estruturarem e os insumos orgânicos estarem disponíveis no mercado. Após o 
uso dos insumos não certificados é necessário analisar se o solo demonstra a existência de componentes tóxicos. A expansão significativa dos mercados de orgânicos conduz alguns atores para a produção de insumos para a agricultura certificada orgânica. Há atores que utilizam rejeitos industriais e agrícolas como cinzas, esterco e casca de ovos para produzir compostos.

Outro aspecto interessante que vem sendo observado nos mercados de insumos orgânicos é a existência de insumos com a certificação orgânica. Dentre eles estão, principalmente, aqueles destinados à renovação da fertilidade do solo. Mas, esses podem estar inacessíveis para alguns agricultores localizados em áreas mais longínquas ou onde a agricultura orgânica começou a se desenvolver recentemente. Diante desse cenário e para não inviabilizar a produção orgânica, como já foi apontado acima, as certificadoras permitem o uso de insumos de origem convencional até que os insumos com certificação orgânica estejam ao alcance dos agricultores.

Relatos dos agricultores orgânicos apontam que vem se tornando frequente o contato de empresas produtoras de insumos orgânicos oferecendo os seus produtos. Particularmente em São Paulo, observa-se a presença de muitas dessas empresas. Alguns agricultores adquirem esses insumos, mas nem sempre os resultados são bons, pois, quando o agroecossistema está equilibrado e há matéria-orgânica no solo, não são necessárias reposições nutricionais. Casos como esses de desnecessidade de aplicações de insumos foram verificados para culturas como a banana, uvas e amora. Os agricultores dizem que, nos primeiros anos após a transição, é necessário incrementar o solo de maneira regular com matéria orgânica e, até certo ponto, insumos químicos. Mas, a partir de um determinado momento, ressaltam que esses insumos têm sua quantidade reduzida ano após ano, chegando ao ponto de não ser necessário haver a reposição. Ou há necessidade de alguma aplicação de calda ou preparado quando aparece algum sinal de pragas que, segundo os agricultores, está relacionada ao clima e à ocorrência de excesso ou ausência de chuva.

Nos casos em que os agricultores ou empresas dedicam-se com maior intensidade à produção orgânica em monocultivos, observa-se a necessidade da reposição de nutrientes ao solo, bem como a criação e soltura de "inimigos naturais". De modo similar, levantamento de experiências relacionadas à produção de insumos para a agricultura orgânica indica que existe elevada procura por determinados insumos orgânicos em cultivos onde há exploração intensiva do solo. A procura por insumos orgânicos ocorre também quando se objetiva acelerar a recuperação do solo e obter retornos econômicos e produtivos rápidos.

Sabe-se que, para um solo degradado voltar a sustentar cultivos agrícolas, é necessário acrescentar matéria orgânica e cobertura verde por um período mínimo de cinco anos. Nesse sentido, destaca-se que, se o próprio agricultor não passar por um processo de transição, não conseguirá permanecer na agricultura orgânica, na medida em que é necessário estar realmente convicto e possuir outras fontes de subsistência para suportar o período de transição do agroecossistema. A parceria com outros agricultores e organizações facilita a passagem pelo período de transição.

\section{DISCUSSÃO DOS RESULTADOS}

A partir dos resultados apresentados em relação aos três produtores e a partir dos dados complementares, é possível, ainda que de forma superficial, fazer algumas análises acerca da apropriação dos insumos orgânicos. Observa-se a existência de alguns indícios da convencionalização dos orgânicos. Eles aparecem com maior intensidade para os agricultores especializados. Os principais indícios da convencionalização de orgânicos encontrados entre os agricultores consultados são: o modo como ocorre a produção dos shiitakes, com alto 
emprego de tecnologia operado em sistema de monocultivo que ocorre em ambiente estéril; a especialização produtiva; a alta dependência externa de insumos e uma incipiente integração produtiva. Quanto ao uso dos insumos de origem agroquímica, onde os de qualidade orgânica não estão disponíveis, destaca-se que o tratamento dado aos cultivos é que é orgânico, não necessariamente os insumos são orgânicos.

Além desses pontos discutidos acerca do processo de convencionalização dos mercados de orgânicos, outros aspectos podem ser trazidos para averiguar minimamente o processo de apropriacionismo dos insumos usados na agricultura orgânica. Observa-se a existência de algumas semelhanças entre o processo de apropriação que ocorreu e que culminou nos atuais complexos agroindustriais, sistemas agroalimentares e na agricultura agroquímica. Um aspecto é que não há dúvidas da existência de muitas empresas produzindo insumos orgânicos, principalmente compostos e adubos. Verifica-se então que os procedimentos de apropriação industrial de processos antes relativos ao ambiente rural estão ocorrendo, em alguma medida, nos mercados de orgânicos. Nota-se que as mesmas empresas estabelecidas como complexos agroindustriais por meio da apropriação dos insumos da agricultura agroquímica estão também produzindo insumos para a agricultura orgânica. Essas organizações estão disponibilizando os insumos orgânicos aos agricultores da mesma forma que os insumos da agricultura convencional são ofertados: nas revendas, agropecuárias e por meio da assessoria de técnicos que visitam os agricultores lhes estimulando a usar os insumos orgânicos produzidos pelas firmas nas quais trabalham.

Entretanto, não se verificou um processo de apropriação dos insumos orgânicos nas mesmas proporções assumidas na agricultura agroquímica. Isso não ocorreu por dois motivos principais. Primeiro, a agricultura orgânica está em estágio inicial de desenvolvimento, podendo se intensificar (ou não) o processo de apropriacionismo. Segundo, a agricultura orgânica apresenta-se resguardada do processo de apropriação visualizado na agricultura agroquímica. Esse resguardo remete à capacidade que os agroecossistemas manejados ecologicamente têm de se sustentarem sem incrementos nutricionais devido aos processos de ciclagem de nutrientes. Essa é uma característica da agricultura orgânica que, com certeza, dificulta e vai dificultar a ocorrência da apropriação dos insumos orgânicos em moldes parecidos aos visualizados na agricultura agroquímica.

\section{CONSIDERAÇÕES FINAIS}

Neste artigo objetivou-se averiguar em que medida ocorre o processo de apropriação dos insumos usados na agricultura orgânica. Para isso, buscaram-se dados sobre o uso dos insumos com agricultores certificados orgânicos, agroindústrias produtoras de insumos e técnicos em Santa Catarina, Rio Grande do Sul, Paraná e São Paulo.

Conforme os dados apresentados e discutidos, nota-se que os agricultores especializados são os que apresentam em maior número e intensidade sinais da convencionalização dos orgânicos, dentre eles os vinculados ao apropriacionismo. Entre os agricultores havia como indícios a especialização produtiva, a dependência externa de insumos, o uso de estruturas altamente tecnificadas e a presença de características da integração produtiva. $\mathrm{O}$ uso de insumos de origem convencional foi adotado com ressalvas, pois há baixa oferta dos insumos orgânicos em certas regiões.

Com relação ao apropriacionismo percebeu-se que esse é um aspecto pouco presente entre os atores investigados. Muitos dos insumos orgânicos encontrados no mercado vêm sendo produzidos pelas mesmas empresas que produzem insumos para a agricultura agroquímica. No entanto, a agricultura orgânica operada em sistemas diversificados encontra resguardo dessa ação de empresas do capital agroindustrial por ter como uma de suas 
principais características a capacidade de gerar, ao longo do tempo e por seus próprios meios, os nutrientes e especificidades necessários aos cultivos agrícolas.

Evidentemente que as considerações dessa pesquisa remetem a um processo que está em curso. As considerações apontadas aqui não buscam ser conclusivas. Há necessidade de maiores aprofundamentos com a realização de pesquisas paralelas sobre o tema do apropriacionismo dos insumos orgânicos. Pesquisas estas que devem ocorrer em paralelo com as da convencionalização dos mercados de orgânicos.

\section{Agradecimento}

A presente pesquisa contou com apoio financeiro da Coordenação de Aperfeiçoamento de Pessoal de Nivel Superior (CAPES).

\section{REFERÊNCIAS}

ABREU, L. et al. Relações entre agricultura orgânica e agroecologia: desafios atuais em torno dos princípios da agroecologia. Desenvolvimento e Meio Ambiente, Curitiba, v. 26, p. 143160, jul-dez. 2012. Disponível em: <https://revistas.ufpr.br/made/article/view/26865>. Acesso em: 4 set. 2019.

ALTIERI, M.; NICHOLLS, C. Agroecologia: resgatando a agricultura orgânica a partir de um modelo industrial de produção e distribuição. Agroecologia, Pelotas, RS, n. 27, p. 141-152, jul-dez. 2003.

ALMEIDA, G.; ABREU, L. Estratégias produtivas e aplicação de princípios da agroecologia: o caso dos agricultores familiares de base ecológica da cooperativa dos agropecuaristas solidários de Itápolis - COAGROSOL. Revista de Economia Agrícola, São Paulo, v. 56, n. 1, p. 37-53, 2009. Disponível em:

<https://ainfo.cnptia.embrapa.br/digital/bitstream/item/143841/1/2009AP-18.pdf $>$. Acesso em: 4 set. 2019.

BRASIL. Ministério da Agricultura, Pecuária e Abastecimento. MAPA. Orgânicos. 2015. Disponível em: 〈http://www.agricultura.gov.br/desenvolvimento-sustentavel/organicos >. Acesso em: 12 jan. 2016.

BRASIL. Ministério da Agricultura, Pecuária e Abastecimento. MAPA. Cadastro de produtores orgânicos. 2021. Disponível em: <https://www.gov.br/agricultura/ptbr/assuntos/sustentabilidade/organicos/cadastro-nacional-produtores-organicos $>$. Acesso em: 8 jul. 2021.

BUCK, D.; GETZ, C.; GUTHMAN, J. From farm to table: the organic vegetable commodity chain of northern California. Sociologia Ruralis, Assen, v. 37, p. 3-20, 1997. Disponível em: <https://onlinelibrary.wiley.com/doi/abs/10.1111/1467-9523.00033>. Acesso em: 4 set. 2019.

CANDIOTTO, L.; MEIRA, S. Agricultura orgânica: uma proposta de diferenciação entre estabelecimentos rurais. CAMPO-TERRITÓRIO: Revista de geografia agrária, v. 9, n. 19, p. 149-176, out. 2014. Disponível em:

<http://www.seer.ufu.br/index.php/campoterritorio/article/view/26083 > . Acesso em: 4 set. 2019. 
G1. Unilever compra empresa brasileira produtora de orgânicos Mãe Terra. 2017. Economia. Disponível em: <https://g1.globo.com/economia/negocios/noticia/unileveranuncia-compra-da-empresa-brasileira-de-organicos-mae-terra.ghtml > . Acesso em: 30 jun. 2019.

GODOY, A. S. Introdução à pesquisa qualitativa e suas possibilidades. Revista de Administração de Empresas, São Paulo, v. 35, n. 2, p. 57-63, mar-abr 1995. Disponível em: <http://www.scielo.br/pdf/rae/v35n2/a08v35n2.pdf>. Acesso em: 29 mar. 2017.

GOODMAN, D.; SORJ, B.; WILKINSON, J. Da lavoura às biotecnologias: A agricultura e indústria no sistema internacional. Rio de Janeiro: Centro Edelstein de Pesquisas Sociais, 2008. 204p.

GUTHMAN, J. The trouble with 'organic lite' in California: a rejoinder to the 'conventionalisation' debate. Sociologia Ruralis, Assen, v. 44, n. 3, p. 301-316, 2004.

Disponível em: 〈https://onlinelibrary.wiley.com/doi/abs/10.1111/j.1467-9523.2004.00277.x >. Acesso em: 4 set. 2019.

HALL, A.; MOGYORODY, V. Organic farmers in Ontario: an examination of the Conventionalization Argument. Sociologia Ruralis, Assen, v. 41, n. 4, p. 399-422, out. 2001. Disponível em: 〈https://onlinelibrary.wiley.com/doi/abs/10.1111/1467-9523.00191>. Acesso em: 4 set. 2019.

IDEC - Instituto Brasileiro de Defesa do Consumidor. Quer pagar quanto? Revista do Idec, p. 16-20, abr. 2010. Disponível em:

<http://www.idec.org.br/uploads/revistas_materias/pdfs/2010-04-ed142-capaorganicos 1.pdf >. Acesso em: 24 nov. 2015.

IFOAM - International Federation of Organic Agriculture Movement. Princípios da agricultura biológica: Preâmbulo. Alemanha: IFOAM HEAD OFFICE, 2005. Disponível em: 〈http://www.ifoam.bio/sites/default/files/poa_portuguese_web.pdf $>$. Acesso em: 14 set. 2015.

LAMINE, C.; BELLON, S. Conversion to organic farming: a multidimensional research objetc at the crossroads of agriculture and social sciences: a review. Agronomy for Sustainable Development, Paris, v. 29, p. 97-112, 2009. Disponível em: <https://hal.archives-ouvertes.fr/hal-00886434/document>. Acesso em: 4 set. 2019.

MATTAR, F. N. Pesquisa de Marketing: Metodologia, planejamento, execução e análise. 3 ed. São Paulo: Atlas, 2001. 504p.

NIEDERLE, P.A.; ALMEIDA, L. A nova arquitetura dos mercados para produtos orgânicos: o debate da convencionalização. In: NIEDERLE, P.A.; ALMEIDA, L.; VEZZANI, F. M. (Org.). Agroecologia: práticas, mercados e políticas para uma nova agricultura. Curitiba: Kairós, 2013, v. 1, p. 23-68.

OELOFSE, M. et al. Organic farm conventionalisation and farm pratices in China, Brazil and Egypt. INRA, 2011. 
PARRA FILHO, O. et al. A convencioalização na produção de sementes na agricultura orgânica brasileira. RESR, Piracicaba, v. 56, n. 4, p. 565-582, out./dez. 2018. Disponível em: $<$ http://www.scielo.br/scielo.php?script=sci_arttext\&pid=S0103$20032018000400565 \& \operatorname{lng}=\mathrm{pt} \& n r m=i$ so $\&$ tlng $=\mathrm{pt}>$. Acesso em: 3 set. 2019.

ROVER, O.; LAMPA, F. Rede Ecovida de agroecologia: articulando trocas mercantis com mecanismos de reciprocidade. Agriculturas, Rio de Janeiro, v. 10, n. 2, p. 22-25, jun. 2013. Disponível em: <http://aspta.org.br/wp-content/uploads/2013/09/Revista-AgriculturasV10N2-Artigo-4.pdf $>$. Acesso em: 3 set. 2019.

SAUTEREAU, N.; BELLON, S. The contribution of conversion to organic food and farming to the analysis of dynamics and governance in transitions towards sustainable agri-food systems. In.: BARBIER, M.; ELZEN, B. (Ed.). System Innovations, knowledge Regimes, and Design Practices: towards transitions for sustainable Agriculture. INRA: 2012. p. 47-68.

SEBRAE- Serviço Brasileiro de Apoio às Micro e Pequenas Empresas. O Mercado para os Produtos Orgânicos Está Aquecido. 2015. Disponível em:

<http://www.sebrae.com.br/sites/PortalSebrae/artigos/o-mercado-para-os-produtos-organicosesta-aquecido,5f48897d3f94e410VgnVCM1000003b74010aRCRD>. Acesso em: 31 mar. 2017.

STAKE. R. E. Case studies. In: DENZIN, N. K.; LINCOLN, Y. S. (Ed.). Handbook of Qualitative Research. London: Sage, 2000. v. 1, p. 435-454. 